\title{
A nuanced role of the small loop of hepatitis $B$ virus small envelope protein in virion morphogenesis and secretion
}

\author{
Chih-Hsu Chang ${ }^{1,2}$, Shu-Fan Chou ${ }^{3}$ and Chiaho Shih ${ }^{2,4^{*}}$ (1)
}

\begin{abstract}
Background: The virion secretion mechanism of human hepatitis B virus (HBV) remains to be investigated. In our current study, we characterized a reverse transcriptase mutant, which changed from the YMDD motif to YMHA. We noted that this mutant YMHA secreted no virions in the medium. Because of the overlapping open reading frame (ORF) between the polymerase and the envelope genes, the lack of virion secretion is likely due to corresponding concurrent mutations in a small loop of the envelope protein (HBsAg, HBV surface antigen). In literature, small loop mutations are thought to affect virion secretion of hepatitis delta virus (HDV), but not HBV.
\end{abstract}

Methods: Here, we revisited the relationship between the small loop and virion secretion by site-directed mutagenesis and native agarose gel electrophoresis.

Results: A proline substitution at residue 196 or 198 in the small loop blocked both HBV genome-containing and genome-free virion secretion, but not the secretion of 22-nm HBsAg subviral particles. Surprisingly, a leucine substitution at residue 196 enhanced genome-containing virion secretion. It is also intriguing that a proline-197, sandwiched by residue 196 and 198, exhibited no apparent defect in secreted virions, with or without containing an HBV genome. By complementation assay, we demonstrated that the wild type small envelope protein alone is sufficient to rescue the virion secretion defect of a small loop mutant M198P.

Conclusions: The effect of the small loop mutation of HBV small envelope protein on virion secretion is positiondependent. It warrants further investigation how the small loop of HBsAg plays a subtle role in HBV morphogenesis and secretion of virions with or without containing an HBV genome.

Keywords: Hepatitis B virus, HBV, Virion secretion, Envelope protein, Small loop, Proline substitution

\section{Background}

Hepatitis B virus (HBV) is a human hepatotropic DNA virus (hepadnavirus) $[1,2]$. Chronic active hepatitis $\mathrm{B}$ patients have a higher risk to develop liver cirrhosis, liver failure and hepatocellular carcinoma. At present, no treatment can effectively eradicate the virus from chronic patients [3]. Therefore, long term treatment is required to

\footnotetext{
*Correspondence: cshih@kmu.edu.tw

${ }^{2}$ Institute of Biomedical Sciences, Academia Sinica, Taipei, Taiwan

Full list of author information is available at the end of the article
}

inhibit viral reactivation from the HBV reservoir. Some HBV patients are coinfected with hepatitis delta virus (HDV) leading to more severe liver diseases [4]. Like a parasite virus to $\mathrm{HBV}, \mathrm{HDV}$ is dependent on the envelope protein of $\mathrm{HBV}$ for viral entry and virion secretion.

HBV surface antigen (HBsAg) is a group of structurally related envelope proteins, including large (L), middle (M) and small (S) envelope. In addition to the envelope protein, HBV also encodes core (capsid) protein for nucleocapsid, polymerase (pol) for pregenomic RNA encapsidation, reverse transcription, and DNA synthesis. In the cell culture transfection system, a number of viral original author(s) and the source, provide a link to the Creative Commons licence, and indicate if changes were made. The images or other third party material in this article are included in the article's Creative Commons licence, unless indicated otherwise in a credit line to the material. If material is not included in the article's Creative Commons licence and your intended use is not permitted by statutory regulation or exceeds the permitted use, you will need to obtain permission directly from the copyright holder. To view a copy of this licence, visit http://creativecommons.org/licenses/by/4.0/. The Creative Commons Public Domain Dedication waiver (http://creativeco mmons.org/publicdomain/zero/1.0/) applies to the data made available in this article, unless otherwise stated in a credit line to the data. 
and subviral particles can be detected in the medium. The best known subviral particles are the non-infectious HBsAg particles around 22-nm in diameter. Enveloped viral particles in the extracellular compartment include genome-containing virions and genome-free empty virions. Empty virions can be detected in patients and in cell culture [5-11]. Non-enveloped particles in the medium include genome-containing nucleocapsids and genomefree empty capsids. The mechanisms for the assembly and release of these various viral and subviral particles are highly complicated, and remain to be elucidated.

It is known that both large and small envelope proteins are essential to virion secretion [12]. The fold of the small envelope protein on the membrane predicts the existence of two cytosolic loops [13, 14], designated as CYL-I and CYL-II (Fig. 1A; [15]). In this paper, CYL-II is referred to as a small loop (as opposed to the CYL-I large loop). Previously, deletion of the $S$ protein residues $24-28$ at the large loop CYL-I blocked HDV virion secretion, yet, no effect on the secretion of HBsAg subviral particles [16]. Serial deletions by $4-6$ amino acids at this CYL-I large loop were shown to block HBV virion secretion [17]. In addition, a single amino acid substitution R79K near the end of the large loop also blocked HBV virion secretion, while the secretion of HBsAg subviral particles was normal. In our earlier studies, a naturally occurring $\mathrm{S}$ gene mutation L77R at the large loop CYL-I resulted in more than tenfold reduced HBV virion secretion, and 2.8-fold reduced $\mathrm{HBsAg}$ in the medium of transfected $\mathrm{HuH}-7$ cells [18]. Confocal microscopy revealed that the L77R mutant HBsAg are largely accumulated within the ER and Golgi. This phenomenon can be rescued by another naturally occurring mutation W74L in the same large loop. Taken together, the large loop of the $\mathrm{S}$ protein appears to play a role in virion secretion of both HDV and HBV.

The small loop CYL-II is located near the C-terminus of the $\mathrm{S}$ protein (Fig. 1A). Site-directed mutagenesis at CYL-II indicated that the assembly of stable HDV particles is dependent on the small loop, including a tryptophan-196 [19]. Indeed, a tryptophan-rich motif (W196, W199, and W201) in the small loop were shown to have a matrix-like function for S-HBsAg interaction with the large delta antigen (L-HDAg) in HDV assembly [20].
However, unlike HDV, this tryptophan-rich motif in the small loop were dispensable for both assembly and infectivity of HBV virions [15]. In another study, the disparity between HBV and HDV in the requirements of the small loop in virion assembly and secretion, was confirmed [21]. Triple alanine substitutions at the small loop affected no HBV secretion of either genome-free empty virions or genome-containing virions. In literature, unlike the large loop, the small loop of HBsAg is required in virion secretion only for HDV, but not HBV.

In this study, amino acid substitutions at residue 196 or 198 in the small loop altered HBV genome-containing virion secretion. It is surprising to note here that the same proline substitution at a neighboring position 197, adjacent to 196 and 198, exhibited no phenotype in virion secretion. Using a small loop mutant M198P defective in virion secretion, we conducted a complementation experiment, and demonstrated that it is the small $\mathrm{S}$ envelope protein, but not $L$ and $M$, that can successfully restore virion secretion. It merits further investigation in the future on HBV morphogenesis and virion secretion.

\section{Materials and methods \\ Cell line and transfection}

HuH-7 cells were maintained in DMEM medium (Invitrogen) supplemented with $10 \%$ fetal bovine serum (Gibco), $100 \mathrm{U} / \mathrm{ml}$ penicillin and $100 \mu \mathrm{g} / \mathrm{ml}$ streptomycin. HepG2-NTCP cells were generated by NTCP expressing lentivirus and maintained in DMEM medium (Invitrogen) supplemented with $10 \%$ fetal bovine serum (Gibco), $100 \mathrm{U} / \mathrm{ml}$ penicillin, $100 \mathrm{ug} / \mathrm{ml}$ streptomycin and 20ug/ $\mathrm{ml}$ Blasticidin (Invivogen). Cells were transfected with plasmids by PolyJet ${ }^{\mathrm{TM}}$ In Vitro DNA Transfection Reagent (Signagen) according to the Manufacturer's instructions.

\section{Plasmids}

A wild type HBV replicon plasmid, pCHT-9/3091, contains a 1.1-mer HBV genome (ayw). Plasmid pCHT-9/3091-pol-YMHA is defective in viral DNA synthesis due to a YMHA mutation at the catalytic site of the reverse transcriptase domain. A pol-null replicon was derived from pCHT-9/3091 [22], with a methionine initiation codon mutation from ATG to ACG [23, 24],

\footnotetext{
(See figure on next page.)

Fig. $1 \mathrm{HBV}$ virion secretion is blocked by mutations within a cytosolic small loop of the envelope protein (HBsAg). A The predicted topology of the folded HBV envelope protein on the ER membrane contains a cytosolic large loop CYL-I and a small loop CYL-II. A conceptual model for HBV virion assembly and secretion postulates a matrix role for these two cytosolic loops in their interactions with nucleocapsids. B A motif YMDD in the wild type reverse transcriptase (RT) domain has been engineered into a YMHA motif. Plasmid DNAs of wild type and mutant HBV DNAs were transfected into a human hepatoma cell line HuH-7. This YMHA mutant secreted no virions in the medium as detected by native agarose gel electrophoresis and Western blot analysis using an anti-HBc antibody. The polymerase gene overlaps with the envelope gene. C The YMHA polymerase mutation caused simultaneous changes of amino acid sequences from WMM to CTP at position 196-198 within the small loop of the envelope protein. The CTP triple mutations were dissociated by analyzing individual mutations 196C, 197T, and 198P, respectively. Right panel: Lack of virion secretion was detected only in the triple mutant CTP and a single proline substitution mutant 198P. Red asterisk * highlights the strongly reduced levels of HBC core protein signal of total virions in mutants CTP and M198P
} 
A

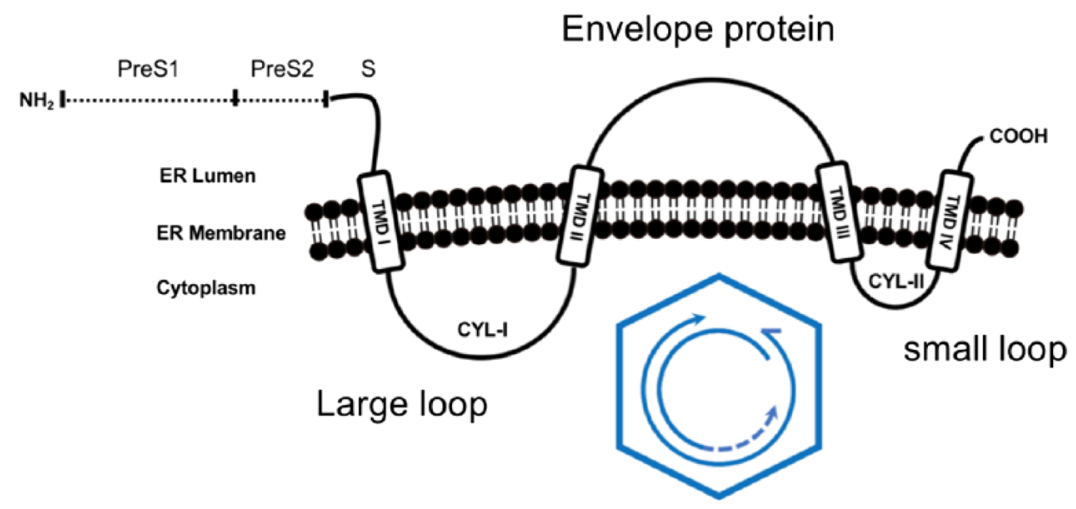

Nucleocapsid

B

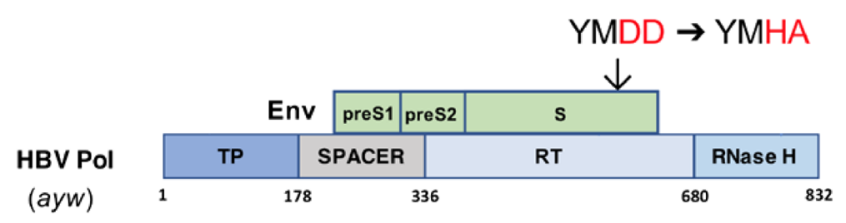

(ayw)

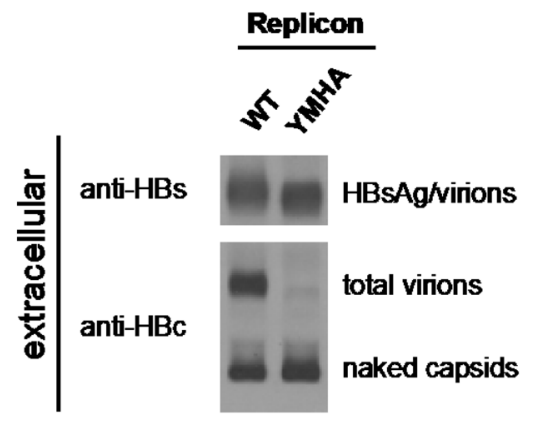

C

(a.a. 196-198)

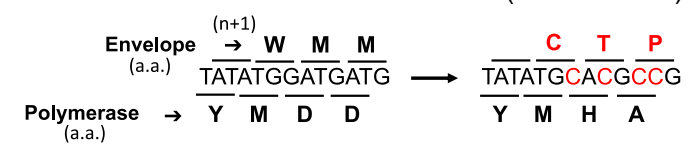
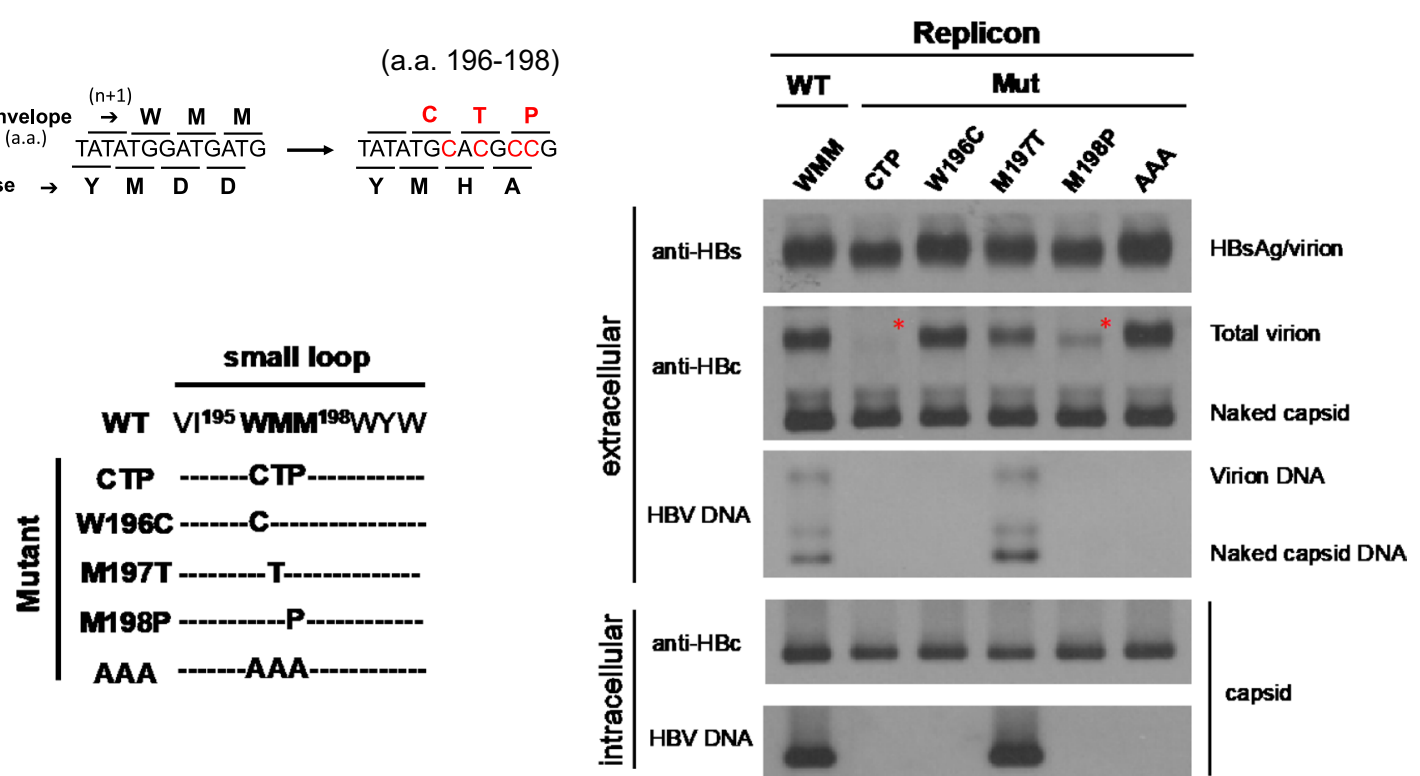

Fig. 1 (See legend on previous page.) 
and the second methionine codon mutation from ATG to TAG. Plasmid pMT-pol is a WT polymerase expression vector [25]. Single small loop mutations, W196C, M197T, and M198P, were introduced individually into the envelope ORF in pCHT-9/3091. Proline substitution mutants W196P, M197P, and M198P, were engineered by introducing a proline into the envelope ORF of the pol-null replicon. Similarly, envelope mutations W196F, W196S and W196L were introduced into the pol-null replicon plasmid. The $\mathrm{L}, \mathrm{M}$, and $\mathrm{S}$ envelope expression vectors were engineered using the pCHT-9/3091-Core null backbone. Methionine initiation codons of $\mathrm{L}, \mathrm{M}$ or $S$ envelope proteins were changed individually from ATG to ACG without affecting the amino acid sequences of the overlapping polymerase ORF. Site direct mutagenesis was performed by using a QuikChange Lightning SiteDirected Mutagenesis Kit (Agilent).

\section{Native agarose gel electrophoresis for western and southern blot analysis}

Culture medium and cell lysates of plasmid-transfected $\mathrm{HuH} 7$ cells were collected at 5 days post-transfection. HBV particles in the medium were precipitated by incubation overnight with 10\% PEG-8000. PEG precipitates were resuspended in TNE buffer $(20 \mathrm{mM}$ Tris $\mathrm{pH} 7.5$, $150 \mathrm{mM} \mathrm{NaCl}, 1 \mathrm{mM}$ EDTA). Aliquotes of viral and subviral particles from cell lysates and media were resolved by $1 \%$ native agarose gel electrophoresis, followed by gel transfer to either nitrocellulose membrane (Amersham) for Western blot, or $\mathrm{N}+$ membrane (Invitrogen) for Southern blot analysis. Detailed procedures of Western and Southern blot analyses were as described elsewhere [26, 27]. Rabbit anti-core antibody was diluted 1:5000 for Western blot analysis as described elsewhere $[28,29]$. HBsAg/virions was detected with goat anti-HBs antibody (Dako) (1:5000). The digoxygenin-labeled fulllength HBV specific DNA probe was used for HBV DNA hybridization in Southern blot analysis.

\section{Immunofluorescence analysis (IFA)}

HBV plasmid-transfected HuH-7 cells were seeded onto glass coverslips $(18 \mathrm{~mm})$ in 6-well plates before fixation with $4 \%$ paraformaldehyde at $48 \mathrm{~h}$ post-transfection. Immunostaining was performed as described $[28,29]$. HBV core protein was stained with a rabbit anti-HBc polyclonal antibody (1:2000). HBsAg was stained with a goat anti-HBs antibody (Dako) (1:200).

\section{Immunoprecipitation and western blot assay}

HBV plasmid-transfected HuH-7 cells and HepG2-NTCP cells were seeded in a 6 well plate around $16 \mathrm{~h}$ before transfection. Transfected cells were lysed at 5 day posttransfection. Procedures of immunoprecipitation and
Western blot assays were performed as described previously [28]. For HBsAg immunoprecipitation, rabbit antiHBs antibody (Novus) $(4 \mu \mathrm{g})$ was incubated overnight at $4{ }^{\circ} \mathrm{C}$ with protein G-coated magnetic beads. In Western blot analysis, $\mathrm{HBV}$ core protein was visualized with an anti-HBc antibody (1:2000), while HBsAg was visualized with a horse anti-HBs antibody (Abcam) (1:1000). Large and middle envelope proteins were detected with a mouse anti-preS2 antibody (Institute of Immunology, Japan) (1:1000).

\section{Protein topology prediction}

The topology of the folded small S protein on the membrane were predicted by the software TMHMM v2.0 (http://www.cbs.dtu.dk/services/TMHMM/).

\section{Quantification of $\mathrm{HBV}$ virion DNA}

$\mathrm{HuH}-7$ cells were seeded in a 6-well plate around $16 \mathrm{~h}$ before transfection. Supernatants were collected at 5 day post-transfection. HBV virions were immunoprecipitated using a rabbit anti-HBs antibody (Novus) and protein G-coated magnetic beads at $4{ }^{\circ} \mathrm{C}$ overnight. Immunoprecipitates were resuspended in TNE buffer for nuclease digestion of input plasmid DNA at $37^{\circ} \mathrm{C}$ for $3 \mathrm{~h}$. Viral DNA was extracted by using the High Pure Viral Nucleic Acid Kit (Roche). HBV virion-associated DNA was quantified by qPCR using HBV core-specific primers: forward $5^{\prime}$ GAGTGTGGATTCGCACTCC $3^{\prime}$ and reverse $5^{\prime}$-GAG GCGAGGGAGTTCTTCT $3^{\prime}$ and power SYBR green master mix (ThermoFisher) on Quantstudio 5 (Applied Biosystems). Calculation of HBV genome equivalent (GE) was based on a standard curve of serially diluted HBV replicon plasmid, pCHT-9/3091. Statistical analyses were performed by the GraphPad Prism software. Statistical difference in GE was analyzed by one-way ANOVA test. ${ }^{* * * * \mathrm{P}} \mathrm{P}<0.001 ;$ **: $\mathrm{P}<0.01 ;{ }^{*} \mathrm{P}<0.05$.

\section{Results \\ No virion secretion of polymerase mutant YMHA}

A predicted topology of HBV envelope protein (HBV surface antigen, HBsAg) on the membrane is illustrated in Fig. 1A [13, 14]. There are two cytosolic loops designated as CYL-I (large loop) and CYL-II (small loop) [15]. A conceptual model for virion assembly and secretion had been tested previously $[15-17,19,20]$. This model envisioned that these two loops might serve as a matrix loop in bringing together HBsAg and HBV nucleocapsids or HDV ribonucleoprotein (RNP) complex. As shown in Fig. 1B, we characterized an HBV polymerase (pol) mutant, changing from YMDD to YMHA in the reverse transcriptase (RT) domain. Using the native agarose gel electrophoresis, we discovered by serendipity that mutant YMHA exhibited no detectable virion-associated 
core protein signal in the medium of $\mathrm{HuH}-7$ cells transfected with the pol-RT mutant YMHA. In contrast, both HBV surface protein antigen and naked capsids can be secreted in a normal manner indistinguishable from the wild type HBV control.

\section{Polymerase mutant YMHA contains concurrent envelope mutations}

Because of the overlapping ORFs between pol and HBsAg (Fig. 1B), this YMHA mutant contains concurrent mutations in the envelope ORF, changing from WMM to CTP at amino acid 196-198 (Fig. 1C). Topologically, these CTP mutations happen to fall within a known small cytosolic loop. To find out which specific amino acid change of these three clustering CTP mutations is responsible for the lack of virion secretion, we compared virion secretion among single envelope mutations W196C, M197T, and M198P (left panel, Fig. 1C). In HBV patients and cell culture, a large excess of empty virions are secreted over the genome-containing virions [5-11]. Only the triple mutant CTP and the single mutant M198P are severely deficient in virion secretion (red asterisk, right panel, Fig. 1C). While mutant M197T has a moderate reduction in empty virion secretion, triple mutant AAA and single mutant W196C exhibited a level of empty virion secretion similar to that of wild type (WT) HBV. There was no apparent difference in the amount of intracellular core protein or extracellular HBsAg and naked capsids (right panel, Fig. 1C). Viral DNA synthesis can only be detected in mutant M197T by Southern blot analysis. The rest of mutants displayed no HBV DNA signal due to their concurrent envelope mutations.

\section{Cytoplasmic distribution of $\mathrm{HBsAg}$}

Next, we examined the intracellular distribution of HBsAg between the small loop mutants and wild type HBV by using confocal microscopy (Fig. 2). We detected no apparent difference in the subcellular envelope protein $\mathrm{HBs}$ and core protein $\mathrm{HBc}$ between wild type HBV, triple mutant CTP and single mutant M198P. It is also tempting to speculate that the small loop mutations could affect the core-envelope interaction leading to abnormality in virion morphogenesis and secretion. To address this issue, we conducted immunoprecipitation assay followed by Western blot analysis. As shown in Western blot of Fig. 3A, relative to the WT control, mutants CTP and M198P had reduced levels of small, middle and large envelope proteins, despite their respective core protein levels are similar to each other.

\section{Core-envelope interactions}

In Fig. 3, anti-HBs antibody was used to immunoprecipitate the intracellular lysates of $\mathrm{HuH}-7$ (Fig. 3A) and HepG2-NTCP (Fig. 3B) cells transfected with wild type and small loop mutants. As expected, in the extracellular compartment, while envelope proteins can be detected in WT and proline substitution mutants by Western blot analysis, we detected no core protein signal in mutants (lane 6 and 7, Fig. 3A and B), indicating the lack of virion secretion. In the intracellular compartment, we detected equal intensities of core protein signal (lane 1-3, Fig. 3A and $\mathrm{B})$, suggesting that core-envelope interaction could be normal for mutants CTP and M198P.

\section{A nuanced position effect in the small loop on genome-containing virion secretion}

Based on the results In Figs. 1, 2, 3, the polymerase mutant YMHA (HBsAg mutant CTP) is defective in viral DNA synthesis, and its genome-free (empty) virion secretion is arrested by a proline substitution at the small loop. We asked if a similar phenomenon can be extended to secretion of genome-containing virions. We designed a cotransfection experiment by using a pol-null replicon and a wild type polymerase expression vector pMT-pol. In this experiment, we also asked whether the same phenotypic defect in virion secretion can be observed when proline was introduced into positions other than amino acid 198. As shown in Fig. 4A, left panel, we engineered three replicons containing single mutation W196P, M197P, and M198P in the small loop of the HBsAg envelope. By native agarose gel, followed by Western and Southern blot analyses, we observed again significant reduction in the secretion of virion-associated core protein and virion-associated viral DNA of mutant W196P and M198P (lane 3 and 5, Fig. 4A, right panel). Similar results of virion secretion were confirmed by using qPCR analysis (Fig. 4B). Interestingly, in lane 4, the core protein and viral DNA phenotypes of mutant M197P are almost indistinguishable from those of WT HBV. None of these mutants, including mutants CTP, M198P, and W196P, are predicted to have altered the loop size of CYL-II by bioinformatic analysis [software TMHMM v2.0 (http:// www.cbs.dtu.dk/services/TMHMM/)]. Therefore, the proline substitution effect on genome-containing virion secretion appears to be position-dependent within the small loop.

\section{Drug-resistant polymerase mutant YIDD contains envelope mutations W196L/S}

Therapeutic treatment of hepatitis B patients with nucleot(s)ide analogs can induce the emergence of drugresistant polymerase mutants, particularly with amino 


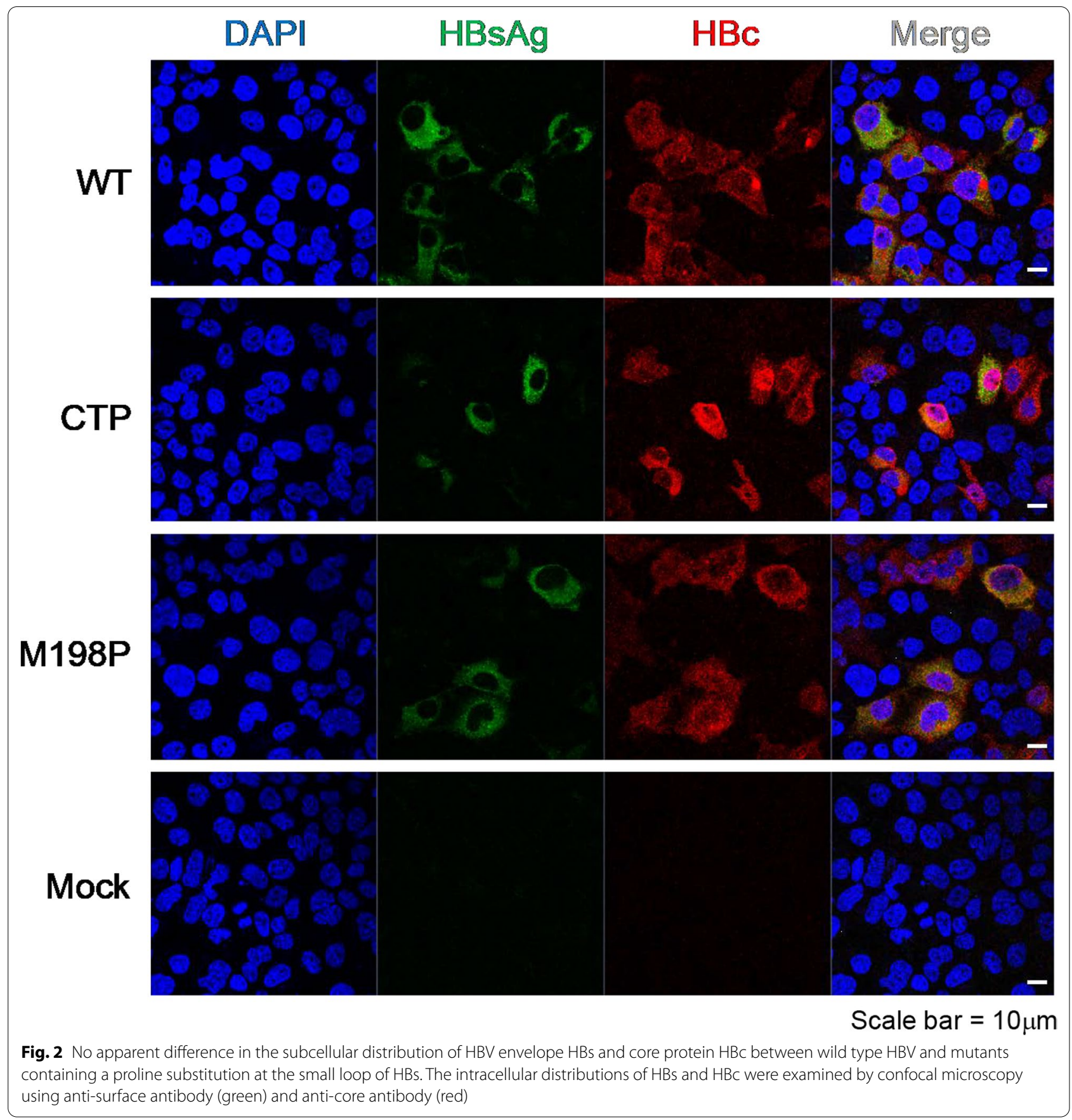

acid substitutions at the YMDD motif [30-32]. Similar to the polymerase mutant YMHA (Fig. 1C), it is anticipated that corresponding envelope mutations can be generated simultaneously in these drug resistant polymerase mutants. We therefore examined the virion secretion of a highly common polymerase mutant YIDD, which contains corresponding envelope mutations W196L or W196S (from tryptophan to leucine or serine) (Fig. 5A). While the lamivudine-resistant mutations corresponding to sW196L/S inhibited secretion of HDV particles [33], it remains unclear if $\mathrm{HBV}$ virion secretion is also affected by the drug resistant polymerase mutants. We found no apparent difference in virion secretion between WTHBV, mutant W196S, and a control mutant W196F (Fig. 5B). Interestingly, we noted that mutant W196L exhibited significantly increased secretion of genomecontaining virions. The results in Fig. 5B were confirmed by using $\mathrm{qPCR}$ analysis (Fig. 5C). 


\section{A Input (HuH-7 cells)}

\section{Replicon}

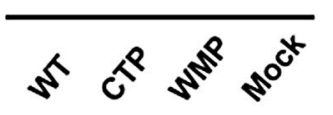

Anti-PreS2

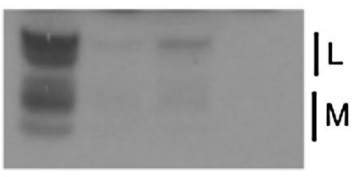

Anti-HBs

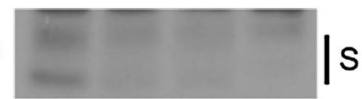

Anti-HBc

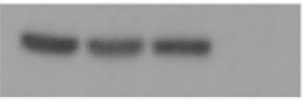

Anti- $\alpha-T u b u l i n$

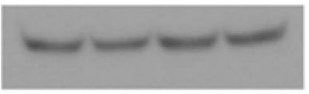

\section{B}

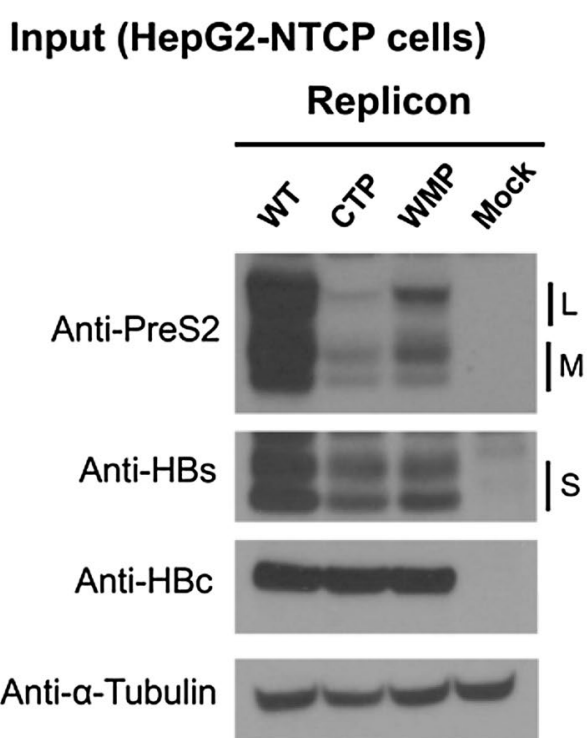

\section{IP: HBs}

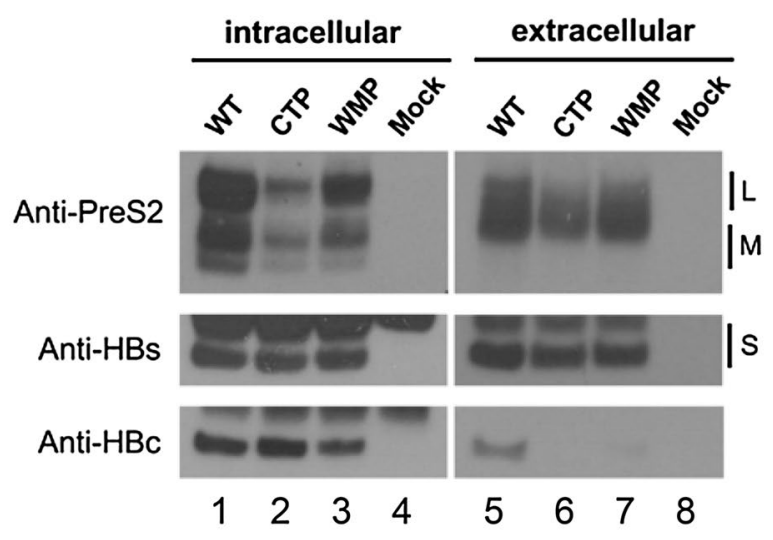

\section{IP: HBs}

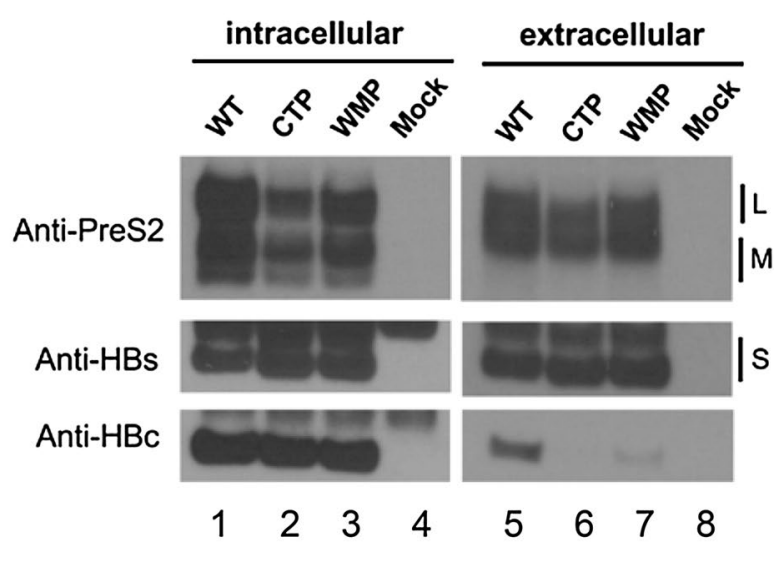

Fig. 3 Similar core-envelope interactions were detected between wild type and small loop mutants in HuH7 cells and HepG2-NTCP cells by immunoprecipitation assay and Western blot analysis. A, B Bead-associated anti-HBs antibody was used to immunoprecipitate intracellular lysate, followed by Western blot analyses using anti-preS2, anti-HBs and anti-core antibodies. Intracellular input. B While intracellular core protein signals were similar between WT and mutants (lanes 1-3), no core protein signal and virion secretion were observed in the extracellular compartment (lanes 6-7). L, M, and S: large, middle and small envelope protein

The small loop from the small S envelope is important for virion secretion

HBV envelope protein consists of six family members, including $\mathrm{L}, \mathrm{M}$, and $\mathrm{S}$ proteins with or without glycosylation (Fig. 6A; [34]). The proline substitution at the small loop is supposed to be present in all members of the $\mathrm{L}, \mathrm{M}$, and $\mathrm{S}$ envelope proteins. It is therefore unclear which envelope protein member(s) really contributes to the lack of virion secretion. We engineered three different envelope protein expression vectors in the core-null replicon context containing a wild type polymerase. These envelope expression vectors can express only one of the three $\mathrm{L}, \mathrm{M}$, or $\mathrm{S}$ envelope protein individually by Western blot analysis (Fig. 6B). Next, we performed complementation assay by cotransfecting HuH-7 cells with each of these three envelope 
A

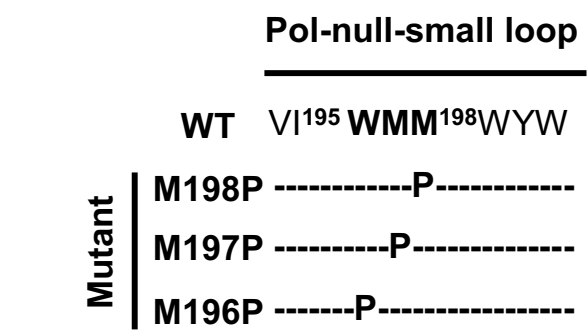

B

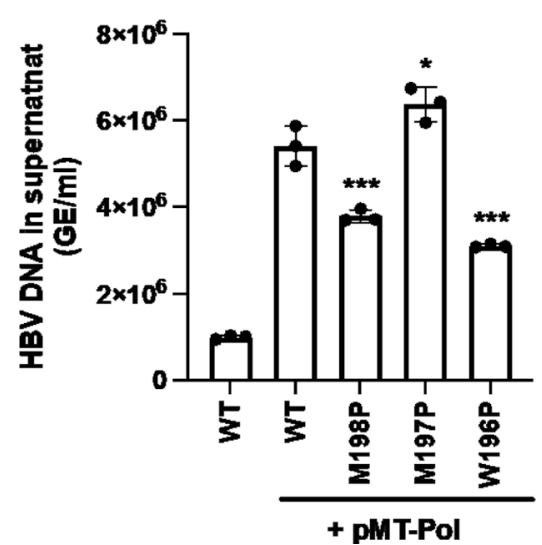

Pol-null replicon

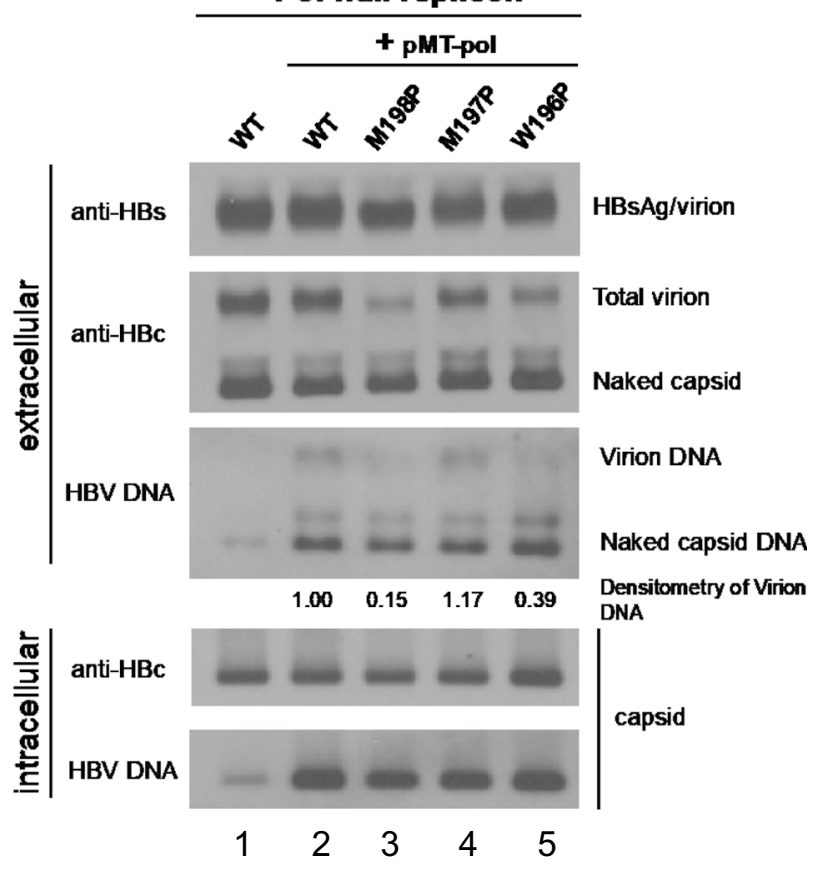

Fig. 4 Secretion of genome-containing virions is also affected by proline substitution in the small loop at amino acid 196-198 in a position-dependent manner. $\mathbf{A} \mathrm{HuH}-7$ cells was cotransfected with a polymerase-deficient replicon plasmid and a wild type polymerase expression vector (pMT-pol). Surprisingly, unlike mutants 196P and 198P, a proline substitution at amino acid 197 resulted in no virion secretion deficiency. Secreted viral particles in the media were enriched by PEG before native agarose gel, followed by Western and Southern blot analyses. Lane 1: A very faint and weak HBV DNA signal can still be visualized from the Pol-null replicon in both intracellular and extracellular panels. Under the strong CMV promoter in the context of pCHT-9/3091 (Materials and Methods), this Pol-null replicon is a bit leaky in polymerase expression and viral DNA synthesis. The virion-associated DNAs were quantified by densitometry and Image J software. B Virion-associated HBV DNA genome in the supernatant of $\mathrm{HuH}-7$ cells was analyzed by qPCR. HBV virions were immunoprecipitated with a rabbit anti-HBs antibody and treated with nuclease digestion before viral DNA extraction. HBV DNA signals of small loop mutants cotransfected with pMT-Pol were compared individually to the WT-HBV control. GE: genomic equivalent. Bar graph statistics by one-way ANOVA tests. ${ }^{* *} \mathrm{P}<0.001 ;{ }^{*} \mathrm{P}<0.05$

protein expression vectors and the pol-null M198P plasmid (Fig. 6C). The defect in genome-containing virion secretion of mutant M198P can be successfully rescued only by cotransfection with the small $\mathrm{S}$ envelope expression vector, but not by the $\mathrm{L}$ and $\mathrm{M}$ expression vectors. Virion-associated viral DNA genome was also rescued simultaneously by the wild type polymerase from the small $S$ envelope expression vector. In the intracellular compartment, cotransfection with different $\mathrm{L}, \mathrm{M}$, and $\mathrm{S}$ expression vectors produced the same levels of core protein and viral DNA (Fig. 6C, bottom). 


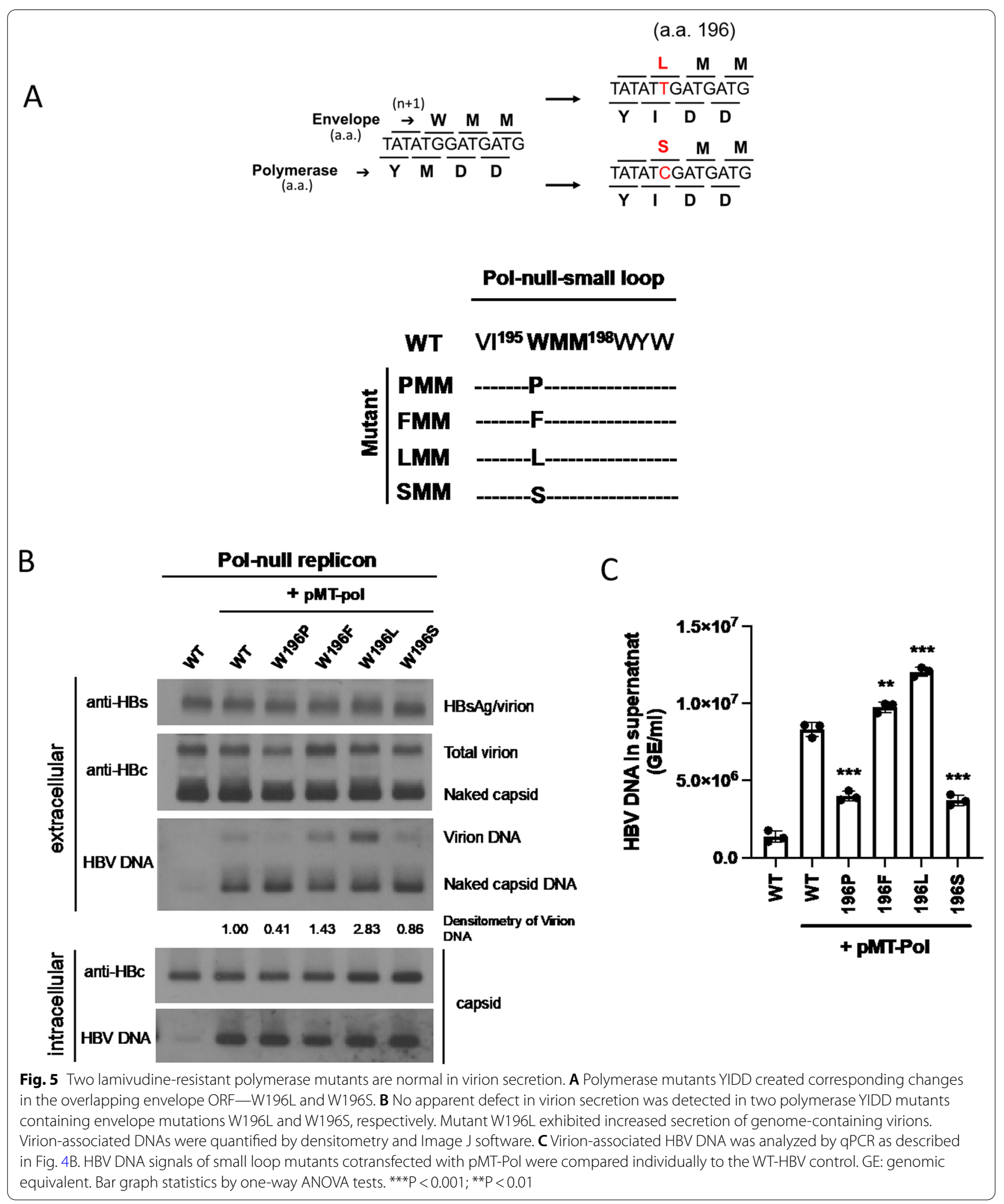


The Southern blot results in Fig. 6C were confirmed by qPCR analysis (Fig. 6D).

\section{Discussion}

HBV virion morphogenesis requires the productive interaction between nucleocapsid particles and the envelope protein(s). Neither HDV nor HBV is known to have a matrix protein which can specialize in facilitating the envelopment of nucleocapsids or an RNP complex. It is tempting to hypothesize that these two cytosolic loops (CYL-I and CYL-II) may serve as a binding interface between envelope proteins on the ER membrane and the nucleocapsids in the cytoplasm. We revisited this hypothesis by focusing on the small loop CYL-II of HBsAg. In previous studies, this small loop had been shown to have a function in virion secretion for HDV, but not HBV [15, 20, 21]. Here, it is surprising that a proline substitution at amino acid 196 or 198 resulted in significantly diminished secretion of virions with (Figs. 4, 5, 6) or without (Fig. 1) containing an HBV genome. If CYL-II is nothing but a small loop without any important structure and function, it is unclear why only W196P and M198P had a phenotypic effect on virion secretion, but not M197P. This position-dependent effect of proline substitution on virion secretion argues for a nuanced role of the small loop in virion morphogenesis and secretion.

The significant reduction in the intracellular HBsAg protein (Fig. 3) in the small loop mutants is not caused by a reduced level of HBsAg mRNA (Additional file 1: Fig. S1). Instead, it could be caused by a post-transcriptional effect, such as protein stability. Given the deceased intracellular level of HBsAg (Fig. 3), it is unclear why the small loop mutants exhibited a similar level of core-envelope interaction complex in the IP-Western blot experiment (Fig. 3). One possibility is that HBsAg particles (22 nm) is well known to exist in large excess over the virion particles $(42 \mathrm{~nm})$. Only a very small amount of HBsAg is needed for virion assembly and morphogenesis. Therefore, the reduction in the intracellular HBsAg level had no significant effect on the core-envelope interaction. Alternatively, since small loop mutants were unable to secrete virions to the extracellular compartment (Fig. 1B and C), the intracellular core-envelope complex was accumulated to a higher level accordingly. In this scenario, the HBsAg reduction effect on the core-envelope interaction is compensated by the accumulation of core-envelope complex arrested in the virion secretion pathway. Finally, the possibility that the mutant core might interact better with the envelopment machinery cannot be excluded. One caveat here is that better binding between core and envelope cannot necessarily be equated to better virion secretion.

Our complementation assay demonstrated that the small loop of the small $S$ envelope protein, but not the large $\mathrm{L}$ and middle $\mathrm{M}$ envelope protein, is required for virion secretion (Fig. 6). In Fig. 6C, the middle form of HBsAg (M) indeed exhibited very weak signal of rescue. However, it is well known that the $M$ envelope protein is not essential for HBV replication and virion secretion in cell culture [12,35]. Although the small loop of the L envelope protein is not required for virion secretion, the $\mathrm{L}$ envelope protein itself is essential to HBV virion morphogenesis and secretion [12]. By serial deletions of the $\mathrm{L}$ protein, a short $\mathrm{C}$-terminal region near the end of the preS1 domain, including arginine-103 to serine-124, was shown to be required for virion maturation $[36,37]$. The interaction between the core protein of nucleocapsids and the preS1 domain of the $\mathrm{L}$ envelope protein was also demonstrated in another experimental setting. Naturally occurring core mutants $197 \mathrm{~L}$ (isoleucine to leucine) or F97L (phenylalanine to leucine), exhibited a so-called "immature secretion" phenotype, which allows excessive secretion of virions containing an immature genome [38-41]. A pre-S1 envelope mutation A119F, changing an alanine (A) to a phenylalanine (F), can erase the immature secretion phenotype of the mutant $197 \mathrm{~L}$ and successfully restore the wild-type-like selective export of the mature genome [42]. Altogether, both L and S envelope proteins are required for virion assembly and secretion.

Longer term treatment of chronic hepatitis B patients with nucleot(s)ide analogs can result in the emergence of drug-resistant polymerase mutants, for example, changing from YMDD to YIDD at the RT domain [30-32]. In

\footnotetext{
(See figure on next page.)

Fig. 6 Only the small envelope protein can rescue the virion secretion defect of the proline substitution mutant M198P. A A cartoon illustrates that the envelope protein ORF can encode a total of 6 different protein products, including large, middle and small envelope proteins. A proline substitution mutation (red asterisk*) is supposed to be present in all 6 envelope proteins. B Western blot analysis detected respective protein products from large, middle and small envelope protein expression vectors. This expression vector is a core-null replicon, which contains no core protein, and is expressing a wild type polymerase and various mutant envelope proteins. Left panel outlines the respective mutations at the initiation codons of large, middle, and small envelope proteins. C Cotransfection with the core-null replicon containing large or middle envelope protein did not restore virion secretion. Only the small envelope protein can successfully rescue the virion secretion defect of the small loop mutant M198P. Red asterisk* highlights the HBC core protein signal and HBV DNA signal by complementation with the small S envelope protein. Virion-associated DNAs were quantified by densitometry and Image J software. D Virion-associated HBV DNA was analyzed by qPCR as described in Fig. 4B. HBV DNA signals of the complementation experiments were compared individually to the mutant M198P. GE: genomic equivalent. Bar graph statistics by one-way ANOVA tests. ***P $<0.001$
} 
A

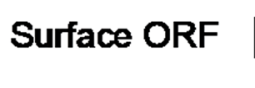

pres1 pres2

S

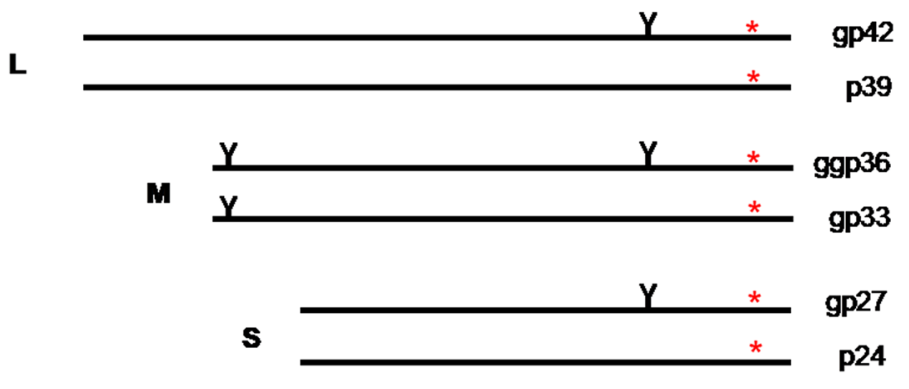

B

In the context of a core-null replicon:

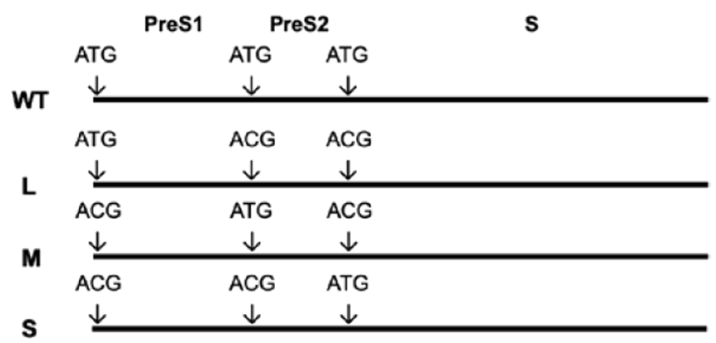

C

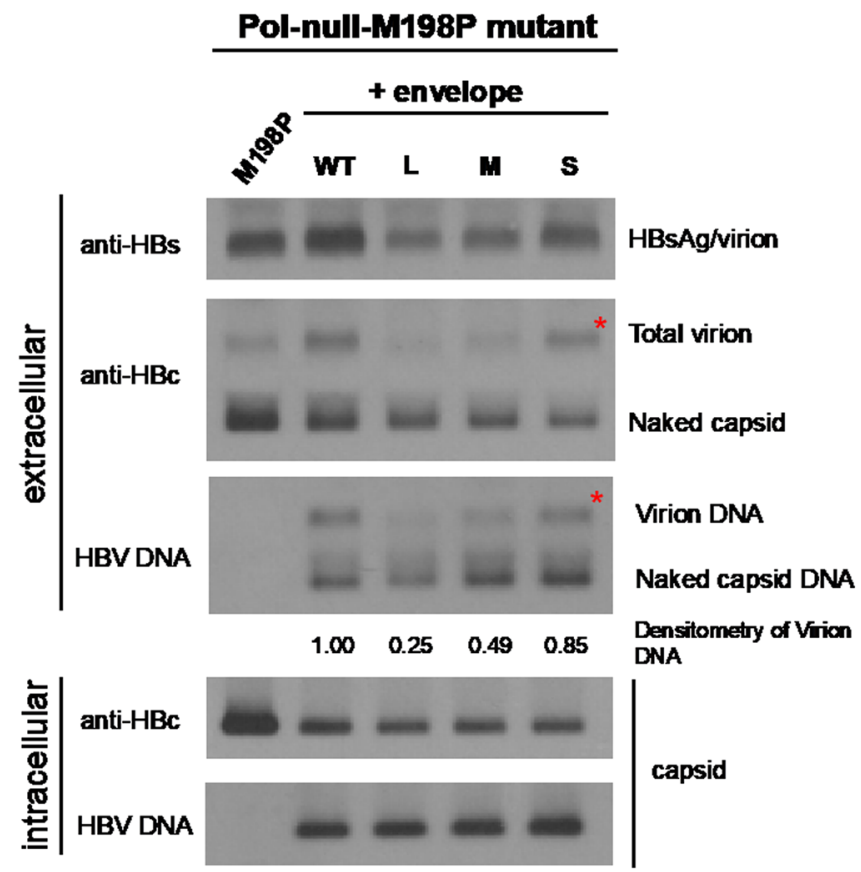

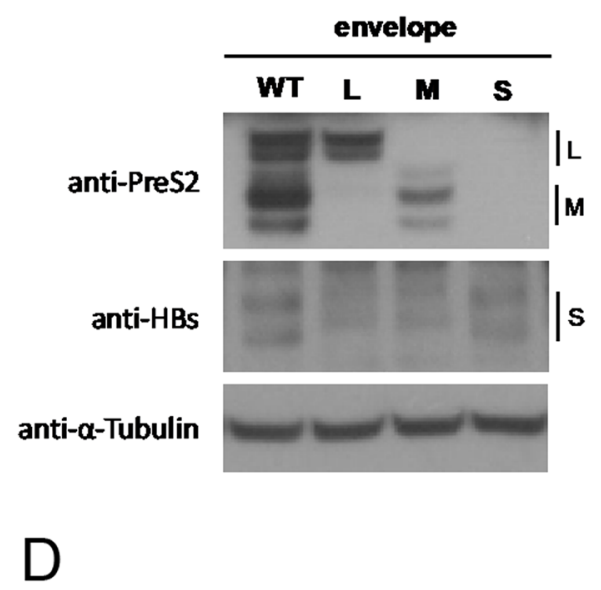

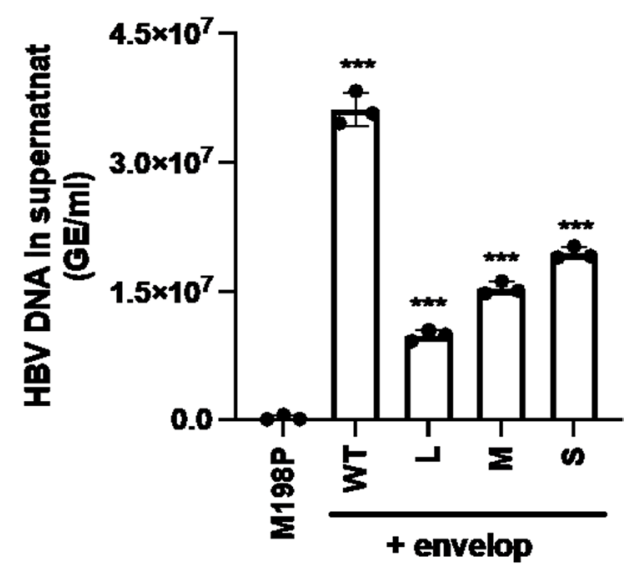

Fig. 6 (See legend on previous page.) 
theory, these kinds of drug-resistant variants should have no problem in virion secretion. Otherwise, they could not have amplified themselves and eventually evolved into a predominant species in treated patients. However, over the past few decades, there is no direct quantitative measurement of the virion secretion efficiency of drug-resistant polymerase variants. In our study, we noted that the polymerase YIDD mutant with a W196S envelope mutation has no apparent defect in $\mathrm{HBV}$ virion secretion (Fig. 5B). However, we were intrigued that the same polymerase mutant YIDD with a different envelope mutation W196L, displayed an even stronger signal of virion-associated DNA, at least in this in vitro $\mathrm{HuH}-7$ cell culture setting. The enhanced virion secretion of mutant W196L provides another evidence that the small loop of the small envelope protein could be engaged in productive core-envelope interaction and virion morphogenesis. As a side note, it is worth mentioning here that neither envelope W196L nor W196S could support HDV virion secretion [33]. Altogether, these virion secretion results could explain the emergence of drug resistant HBV polymerase mutants in patients receiving nucleos(t)ide analog therapy.

A number of host factors involved in HBV particle release have been reported. The Endosomal Sorting Complex Required for Transport (ESCRT) is a house-keeping machinery for both intracellular sorting and trafficking of ubiquitinated protein cargos. Vps4 is a cellular ATPase which is often associated with ESCRT-0 in membrane dynamics. HBV replication and virion secretion can be significantly inhibited by Vps4 dominant negative and ATPase-defective mutants [43, 44]. ESCRT-II, ESCRTIII, Vps4, and gamma 2-adaptin had been reported to be involved in HBV morphogenesis and virion secretion [44-46]. Aberrant expression of HGS (over- or underexpression) of ESCRT-0 can inhibit HBV replication, increase the release of naked capsids, yet reduced the extracellular virions and HBsAg subviral particles [27]. We assumed here that the small loop mutation does not alter the cellular HGS expression level which could then affect virion secretion. Furthermore, it should be noted that the inverse correlation between secreted virions and secreted naked capsids in the HGS studies [27] cannot be extended to our current studies on the envelope small loop. As shown in Figs. 1B, C, 4A, 5B, and 6C, secreted naked capsids have no inverse correlation with secreted virions. In addition, we observed no increased accumulation of intracellular capsid protein and intracellular capsid-associated HBV DNA in the small loop mutants with reduced virion secretion.

Most recently, ERGIC-53, a cellular high-mannose specific membrane lectin, and the endoplasmic reticulum (ER) export machinery COPII (coat protein complex
II), were shown to be important for HBV trafficking and egress [47]. COPII subunits Sec24A, Sec23B, and Sar1 are required for release of both viral and subviral particles. ERGIC-53, Sec24A, and ESCRT, appeared to be involved later in virion secretion after envelopment of nucleocapsids. To date, it remains unclear if CYL-I and CYL-II can bind to any cellular factors involved in the earlier stage of virion morphogenesis and secretion. We speculated here that our current study on the small loop is more related to the early event in virion assembly and morphogenesis in ER/Golgi, while the studies on the ESCRT machinery is more related to the late event in virion secretion in MVB by energy-dependent membrane dynamics.

\section{Conclusions}

We revisited the relationship between HBV virion secretion and the small loop of the small envelope protein. Amino acid substitutions at certain positions within the small loop could affect the egress of both empty virions and genome-containing virions. Understanding better the mechanism of HBV virion secretion could contribute to the development of HBV curative therapy.

\section{Abbreviations \\ HBV: Human hepatitis B virus; HDV: Hepatitis delta virus; HBsAg: Hepatitis B surface antigen; HBc: HBV core protein; Pol: HBV polymerase; RT: Reverse tran- scriptase domain of pol; ORF: Open reading frame; L: Large envelope protein; M: Middle envelope protein; S: Small envelope protein; CYL-I: Large cytosolic loop I; CYL-II: Small cytosolic loop II; ESCRT: Endosomal Sorting Complex Required for Transport; HGS: Hepatocyte growth factor-regulated tyrosine kinase substrate; COPII: Coat protein complex II; Sec24A Sec 23B Sar1: COPII subunit; ERGIC-53: An ER-Golgi intermediate compartment (ERGIC) marker protein.}

\section{Supplementary Information}

The online version contains supplementary material available at https://doi. org/10.1186/s12929-021-00780-0.

Additional file 1. Similar levels of HBV RNAs were detected between wild type and small loop mutants by Northern blot analysis.

\section{Acknowledgements}

We thank the DNA sequencing Core facility and Confocal Microscopy Core Facility at the Institute of Biomedical Sciences, Academia Sinica, Taiwan. The core facility is supported by AS-CFII-108-115.

\section{Authors' contributions}

Experimental design: CHC and CS. Conducted the experiments: CHC and SFC. Data analysis and writing: all authors. All authors read and approved the final manuscript.

\section{Funding}

This research was supported by Kaohsiung Medical University, Academia Sinica [AS-SUMMIT-108] and Ministry of Science and Technology, Taiwan (MOST 110-2314-B-037-130; MOST 110-2811-B-037-524; MOST 109-2314-B-037-137). 


\section{Availability of data and materials}

All data generated in this study are included in this manuscript.

\section{Declarations}

\section{Ethics approval and consent to participate}

Not applicable.

\section{Consent for publication}

Not applicable.

\section{Competing interests}

We declare no competing financial or non-financial interests. The funders had no role in the design of the study; in the collection, analyses, or interpretation of data; in the writing of the manuscript, or in the decision to publish the results.

\section{Author details}

${ }^{1}$ Graduate Institute of Microbiology, College of Medicine, National Taiwan University, Taipei, Taiwan. ${ }^{2}$ Institute of Biomedical Sciences, Academia Sinica, Taipei, Taiwan. ${ }^{3}$ Department of Microbiology, Harvard Medical School, Boston, MA, USA. ${ }^{4}$ Graduate Institute of Medicine, Kaohsiung Medical University, Kaohsiung, Taiwan.

Received: 13 July 2021 Accepted: 23 November 2021 Published online: 01 December 2021

\section{References}

1. Blumberg BS. Hepatitis B virus, the vaccine, and the control of primary cancer of the liver. Proc Natl Acad Sci U S A. 1997;94:7121-5.

2. Shih C, Yang CC, Choijilsuren G, Chang CH, Liou AT. Hepatitis B virus. Trends Microbiol. 2018;26(4):386-7.

3. Shih C, Chou SF, Yang CC, Huang JY, Choijilsuren G, Jhou RS. Control and eradication strategies of hepatitis B virus. Trends Microbiol. 2016;24(9):739-49.

4. Sureau C, Negro F. The hepatitis delta virus: replication and pathogenesis. J Hepatol. 2016;64:S102-16.

5. Gerin JL, Ford EC, Purcell RH. Biochemical characterization of Australia antigen. Evidence for defective particles of hepatitis B virus. Am J Pathol. 1975;81(3):651-68.

6. Kaplan PM, Ford EC, Purcell RH, Gerin JL. Demonstration of subpopulations of Dane particles. J Virol. 1976;17(3):885-93.

7. Alberti A, Diana S, Scullard GH, Eddleston WF, Williams R. Full and empty Dane particles in chronic hepatitis B virus infection: relation to hepatitis B e antigen and presence of liver damage. Gastroenterology. 1978;75:869-74.

8. Sakamoto Y, Yamada G, Mizuno M, Nishihara T, Kinoyama S, Kobayashi T, et al. Full and empty particles of hepatitis B virus in hepatocytes from patients with HBsAg-positive chronic active hepatitis. Lab Invest. 1983;48(6):678-82.

9. Kimura T, Ohno N, Terada N, Rokuhara A, Matsumoto A, Yagi S, et al. Hepatitis $B$ virus DNA-negative dane particles lack core protein but contain a 22-kDa precore protein without C-terminal arginine-rich domain. J Biol Chem. 2005;280(23):21713-9.

10. Schormann W, Kraft A, Ponsel D, Bruss V. Hepatitis B virus particle formation in the absence of pregenomic RNA and reverse transcriptase. J Virol. 2006;80:4187-90

11. Ning X, Nguyen D, Mentzer L, Adams C, Lee H, Ashley R, Hafenstein S, $\mathrm{Hu}$ J. Secretion of genome-free hepatitis B virus-single strand blocking model for virion morphogenesis of para-retrovirus. PLoS Pathog. 2011;7:e1002255.

12. Bruss V, Ganem D. The role of envelope proteins in hepatitis B virus assembly. Proc Natl Acad Sci USA. 1991;88:1059-63.

13. Stirk HJ, Thornton JM, Howard CR. A topological model for hepatitis B surface antigen. Intervirology. 1992;33:148-58.

14. Gudima S, He Y, Chai N, Bruss V, Urban S, Mason W, Taylor J. Primary human hepatocytes are susceptible to infection by hepatitis delta virus assembled with envelope proteins of woodchuck hepatitis virus. J Virol. 2008;82(15):7276-83.

15. Blanchet M, Sureau C. Analysis of the cytosolic domains of the hepatitis $B$ virus envelope proteins for their function in viral particle assembly and infectivity. J Virol. 2006;80(24):11935-45.

16. Jenna S, Sureau C. Effect of mutations in the small envelope protein of hepatitis $B$ virus on assembly and secretion of hepatitis delta virus. Virology. 1998;251(1):176-86.

17. Löffler-Mary H, Dumortier J, Klentsch-Zimmer C, Prange R. Hepatitis $B$ virus assembly is sensitive to changes in the cytosolic $S$ loop of the envelope proteins. Virology. 2000;270(2):358-67.

18. Chua PK, Wang YL, Lin MH, Masuda T, Suk FM, Shih C. Reduced secretion of virions and hepatitis B virus (HBV) surface antigen of a naturally occurring HBV variant correlates with the accumulation of the small $\mathrm{S}$ envelope protein in the endoplasmic reticulum and Golgi apparatus. J Virol. 2005;79:13483-96.

19. Jenna S, Sureau C. Mutations in the carboxyl-terminal domain of the small hepatitis B virus envelope protein impair the assembly of hepatitis delta virus particles. J Virol. 1999;73(4):3351-8.

20. Komla-Soukha I, Sureau C. A tryptophan-rich motif in the carboxyl terminus of the small envelope protein of hepatitis $B$ virus is central to the assembly of hepatitis delta virus particles. J Virol. 2006;80(10):4648-55.

21. Ning X, Luckenbaugh L, Liu K, Bruss V, Sureau C, Hu J. Common and distinct capsid and surface protein requirements for secretion of complete and genome-free hepatitis B virions. J Virol. 2018;92(14):e00272-e318.

22. Nassal $M$. The arginine-rich domain of the hepatitis $B$ virus core protein is required for pregenome encapsidation and productive viral positivestrand DNA synthesis but not for virus assembly. J Virol. 1992;66:4107-16.

23. Roychoudhury S, Shih C. cis rescue of a mutated reverse transcriptase gene of human hepatitis B virus by creation of an internal ATG. J Virol. 1990;64:1063-9.

24. Roychoudhury S, Faruqi A, Shih C. Pregenomic RNA encapsidation analysis of eleven missense and nonsense polymerase mutants of human hepatitis B virus. J Virol. 1991;65:3617-24

25. Radziwill G, Tucker W, Schaller H. Mutational analysis of the hepatitis $B$ virus P gene product: domain structure and RNase $\mathrm{H}$ activity. J Virol. 1990;64:613-20.

26. Chua PK, Tang FM, Huang JY, Suen CS, Shih C. Testing the balanced electrostatic interaction hypothesis of hepatitis B virus DNA synthesis by using an in vivo charge rebalance approach. J Virol. 2010;84:2340-51.

27. Chou SF, Tsai ML, Huang JY, Chang YS, Shih C. The dual role of an ESCRT-0 component HGS in HBV transcription and naked capsid secretion. PLOS Pathog. 2015;11(10):e1005123.

28. Li HC, Huang EY, Su PY, Wu SY, Yang CC, Lin YS, Chang WC, Shih C. Nuclear export and import of human hepatitis B virus capsid protein and particles. PLoS Pathog. 2010;6(10):e1001162.

29. Yang CC, Huang EY, Li HC, Su PY, Shih C. Nuclear export of human hepatitis $B$ virus core protein and pregenomic RNA depends on the cellular NXF1-p15 machinery. PLoS ONE. 2014;9(10):e106683.

30. Shih C. Functional significance of naturally occurring hepatitis B virus variants, p. 3.1-3.19. In: Locarnini S, Lai CL (ed.), Human virus guides—human hepatitis B viruses. 2nd Ed. International Medical Press, London. 2008.

31. Lok AS, Zoulim F, Locarnini S, Bartholomeusz A, Ghany MG, Pawlotsky JM Liaw YF, Mizokami M, Kuiken C. Hepatitis B Virus Drug Resistance Working Group. Antiviral drug-resistant HBV: standardization of nomenclature and assays and recommendations for management. Hepatology. 2007:46(1):254-65.

32. Zoulim F, Locarnini $\mathrm{S}$. Hepatitis B virus resistance to nucleos(t)ide analogues. Gastroenterology. 2009;137(5):1593-608.

33. Vietheer PT, Netter HJ, Sozzi T, Bartholomeusz A. Failure of the lamivudine-resistant rtM204l hepatitis B virus mutants to efficiently support hepatitis delta virus secretion. J Virol. 2005;79(10):6570-3.

34. Stibbe W, Gerlich WH. Characterization of pre-s gene products in hepatitis B surface antigen. Dev Biol Stand. 1983;54:33-43.

35. Tai PC, Suk FM, Gerlich W, Neurath R, Shih C. Hypermodification and immune escape of an internally deleted middle envelope (M) protein of frequent and predominant hepatitis B virus variants. Virology. 2002:292:44-58.

36. Bruss $V$, Thomssen $R$. Mapping a region of the large envelope protein required for hepatitis B virion maturation. J Virol. 1994;68(3):1643-50. 
37. Bruss V. A short linear sequence in the pre-S domain of the large hepatitis B virus envelope protein required for virion formation. J Virol. 1997;71(12):9350-7.

38. Yuan TT, Sahu GK, Whitehead WE, Greenberg R, Shih C. The mechanism of an immature secretion phenotype of a highly frequent naturally occurring missense mutation at codon 97 of human hepatitis B virus core antigen. J Virol. 1999;73:5731-40.

39. Yuan TT, Tai PC, Shih C. Subtype-independent immature secretion and subtype-dependent replication deficiency of a highly frequent, naturally occurring mutation of human hepatitis B virus core antigen. J Virol. 1999:73:10122-8

40. Wu SY, Chang YS, Chu TH, Shih C. Persistence of hepatitis B virus DNA and the tempos between virion secretion and genome maturation in a mouse model. J Virol. 2019;93:e01001-e1019.

41. Shih C, Wu SY, Chou SF, Yuan TT. Virion secretion of hepatitis B virus naturally occurring core antigen variants. Cells. 2020;10(1):43.

42. Le Pogam S, Shih C. Influence of a putative intermolecular interaction between core and the pre-S1 domain of the large envelope protein on hepatitis B virus secretion. J Virol. 2002;76(13):6510-7.

43. Chua PK, Lin MH, Shih C. Potent inhibition of human hepatitis B virus replication by a host factor Vps4. Virology. 2006;354:1-6.

44. Lambert C, Döring T, Prange R. Hepatitis B virus maturation is sensitive to functional inhibition of ESCRT-III, Vps4, and gamma 2-adaptin. J Virol. 2007:81(17):9050-60.

45. Prange R. Host factors involved in hepatitis B virus maturation, assembly, and egress. Med Microbiol Immunol. 2012;201(4):449-61.

46. Stieler JT, Prange R. Involvement of ESCRT-II in hepatitis B virus morphogenesis. PLoS ONE. 2014;9(3):e91279.

47. Zeyen L, Döring T, Prange R. Hepatitis B virus exploits ERGIC-53 in conjunction with COPII to exit cells. Cells. 2020;9(8):1889.

\section{Publisher's Note}

Springer Nature remains neutral with regard to jurisdictional claims in published maps and institutional affiliations.

- fast, convenient online submission

- thorough peer review by experienced researchers in your field

- rapid publication on acceptance

- support for research data, including large and complex data types

- gold Open Access which fosters wider collaboration and increased citations

- maximum visibility for your research: over 100M website views per year

At BMC, research is always in progress.

Learn more biomedcentral.com/submissions 